\title{
To evaluate and compare analgesic effects of wound infiltration with voveron with intravenous injection in cesarean section
}

\author{
Saraf $\mathbf{S}^{1}$, Batra $\mathbf{M}^{2}$, Dr Songir $\mathbf{S}^{3}$, Dr Thakur $\mathrm{KK}^{4}$, Gaikwad $\mathbf{M}^{5}$ \\ ${ }^{1}$ Dr. Smriti Saraf, Associate Professor, ${ }^{2}$ Dr. Mahima Batra, Associate Professor, ${ }^{3}$ Dr. Sheetal Songir, Associate Professor, \\ ${ }^{4}$ Dr. Krishna Kumar Thakur, Resident Anaesthesiology, Dr. M.R. Gaikawad, Professor \& Head Anesthesiology. All are \\ affiliated with Peoples Medical College, Bhopal, MP, India
}

Address for Correspondence: Dr. Smriti Saraf, Dr. Mahima Batra, Department of Anesthesiology, Peoples Medical College , Bhopal (M.P.) India, Email: sumit_bhargava782000@yahoomail.com

\begin{abstract}
Objectives: Postoperative pain mostly results from sensitization of afferent fibers at injury sites driving central sensitization. Recently, peripheral processes have gained attention as mechanism of hyperalgesia, and prostaglandins are among highly sensitizing agents. To date, postoperative administration of a one single intravenous dose of voveron has shown inconclusive efficacy. Rather than a single intravenous dose, the current study evaluates the postoperative analgesic effect of local injection of voveron sodium after cesarean delivery. Methodology: In a prospective randomized, controlled study, 60 patients age group between 18-35 years, scheduled for routine and emergency cesarean surgery were distributed into two groups of 30 patients each. Postoperatively, group [B] was given voveron in wound local injection and group [A] received voveron $75 \mathrm{mg}$ conventionally as intravenous injections. Pain intensity score, onset of analgesia, rescue analgesia doses and overall patient satisfaction score were recorded. Results: Mean onset of analgesia was $8.31 \pm$ 1.5 min with group A as against $4.23 \pm 1.2$ min with group B. Pain Intensity (PPI) score $\leq 1$ was observed in $78.21 \%$ observations belonging to group A and in $50 \%$ observations of group B. Twenty five patients (71.4\%) from group A and 30 patients $(85.7 \%)$ from group B required rescue analgesia. The patient's feedback was graded as very good or good by $78.5 \%$ of the patients in Group-A and $69 \%$ patients in Group-B. Conclusion: Though both drugs are equally safe, Voveron in local wound infusion is faster acting, more potent and efficient analgesic than intravenous. voveron when used for postoperative pain
\end{abstract}

Key words: Postoperative analgesia, Voveron, local injection.

\section{Introduction}

Postoperative pain and hypoxemia are common complications following cesarean sections. Inadequately treated pain results in an increased incidence of complications and morbidity[1]. An ideal analgesic regimen should provide pain relief with minimal side effects and should allow early return of normal function. Local analgesia provides superior quality of pain relief after surgery and avoids many of the side effects of conventional narcotic analgesics [2]. The primary outcome measure compared was quality of analgesia expressed as Present Pain Intensity (PPI) score [3].

Manuscript received: $21^{\text {st }}$ Jan 2016

Reviewed: $01^{\text {st }} \mathrm{Feb} 2016$

Author Corrected: $09^{\text {th }} \mathrm{Feb} 2016$

Accepted for Publication: $19^{\text {th }}$ Feb 2016

\section{Methodology}

A prospective, randomized, study design with two parallel groups was used. After prior approval from Institutional Ethics Committee, this study was conducted at Peoples Medical College and associated Hospital, Bhopal during a period of 3 months on 60 patients, aged group between 18-35 years, scheduled for routine and emergency cesarean sections. Informed written consent was obtained from all patients. Exclusion criteria were severe systemic disorders including diabetes mellitus, hypertension, heart disease; addiction to narcotic drugs; chronic alcoholism; psychiatric disorders; allergy to study drugs and known contraindications to spinal. Patients were randomly 
distributed into two groups of 30 patients each and randomization was concealed.

Group-B $(n=30)$ : received voveron intrawound local injection

Group-A ( $n=30)$ : received voveron intravenously.

Method of Randomization was Blocked randomization. Thirty blocks of two each with treatment allocation of 1:1 for Group- A and Group-B were created with the help of computer software. Coded envelopes (total 30) were used and each envelope was used for two patients leading to random assignment of one subject to one group. For sample size calculation a pilot study was done on 20 patients (each group containing 10 patients). Present Pain Intensity (PPI) score was recorded. PPI score $\leq 1$ was observed in $34(42.5 \%)$ observations in Group-B as against 69(86.25\%) observations from Group-A, out of total 80 observations made in each group. Sample size was calculated to detect effect size of $43.75 \%$ between two groups accepting alpha error 0.05 and $\beta$ error 0.90 was 28 .

In the operating room pre-operative parameters (pulse rate, blood pressure, respiratory rate and oxygen saturation) were noted. Patients were placed in sitting position and under aseptic precautions; a $25 \mathrm{G}$ spinal needle was inserted through the median approach at a suitable space between L3-L4. Physiological parameters e.g. pulse rate, blood pressure, respiratory rate and oxygen saturation, were recorded every $5 \mathrm{~min}$ during operative period and before shifting to postoperative ward. At the end of operation before dressing is done, a bolus of $75 \mathrm{mg}$ voveron diluted in $10 \mathrm{ml}$ of saline was injected in the wound when the patient complained of pain. Group A was given $75 \mathrm{mg}$ injections intravenously. Pulse rate, blood pressure and respiratory rate were recorded along with present pain intensity (PPI) score. The degree of pain was assessed by using the Present Pain Intensity (PPI) scale; $0=$ no pain; 1=mild pain; 2=discomfort; 3=distress; 4=horrible pain and 5=excruciating pain. Highest PPI score was noted. Thus, Percentage of different PPI scores out of total number of observations was used for comparison of two groups.

During this interval if any patient had PPI $>3$, 'rescue top' doses were noted. Any side effect e.g. nausea, vomiting, backache, sedation or drowsiness, hypotension, sign of excessive block or numbness / weakness in limbs was observed. On $2^{\text {nd }}$ postoperative day each patient was interviewed regarding feedback on overall pain relief during the postoperative Period as very good, good, fair or poor. This scale was used to compare both groups as secondary outcome measure regarding quality of analgesia.

Statistical Analysis: Statistical analysis was done using Stata 11 software. Demographic characteristics, hemodynamic parameters, onset of analgesia, quality of analgesia, level of sedation and side effects were compared between two groups and data was analyzed statistically. For continuous variables descriptive statistics (mean and standard deviations) were computed. Comparison of means in Group-B and Group-A was done using unpaired t-test. For categorical data chi-square test was applied. $\mathrm{P}<0.05$ was considered significant.

\section{Results}

Both groups were comparable in respect of demographic characteristics as shown in Table I . Table 2 shows the proforma used to note down our readings .Each patient, after giving analgesia was followed up for 2 hours. Rescue analgesia was given if PPI score was $>3$. Table 3 compares the quality of analgesia among the groups. Voveron when given in wound was found to be faster in action as compared to intravenous group. Mean onset of analgesia was $4.31 \pm 1.5$ min with local injection group as against $8.23 \pm 1.2$ with intramuscular group ( $\mathrm{p}$ value $<0.05$ ). Quality of analgesia was also better with voveron local injection reflected by the fact that Present Pain Intensity (PPI) score was zero (means no pain at all) in only $3.93 \%$ observations belonging to intramuscular group as against $17.5 \%$ observations belonging to local injection group. PPI Score 1 (meaning slight pain) was observed in $46.07 \%$ observations belonging to intramuscular group as against in $78.21 \%$ observations belonging to local injection group. PPI score 3 and 4 was found in 105 and 35 observations respectively belonging to intramuscular group as against in 49 and 12 observations respectively belonging to local injection group. Twenty five patients out of 30 from Local injection group required rescue analgesia as against 30 patients from intravenous group. Overall feedback was graded as very good or good by $78.5 \%$ patients in Group-B and $69 \%$ patients in Group-A. Only one patient from Group-B and 4 from Group-A have graded analgesia as poor. Mild 
hypotension was seen in 5 patients from Group-B and 8 patients in Group-A, which was easily corrected with crystalloid infusions.

\section{Table 1: Patient characteristics}

\begin{tabular}{|l|l|l|l|}
\hline Characteristics & $\begin{array}{l}\text { Group-B } \\
(\mathrm{n} \\
\text { Mean } \pm \text { SD }\end{array}$ & $\begin{array}{l}\text { Group-A } \\
(\mathrm{n} \\
\text { Mean } \pm \text { SD }\end{array}$ & 30) \\
\hline Pge value \\
\hline Height $($ in $\mathrm{cm})$ & $20.86 \pm 13.17$ & $21.57 \pm 10.27$ & $>0.05$ \\
\hline Weight $($ in $\mathrm{Kgs})$ & $159.14 \pm 6.86$ & $161.29 \pm 5.26$ & $>0.05$ \\
\hline
\end{tabular}

\section{Table 2: Quality of analgesia}

\begin{tabular}{|c|c|c|c|c|}
\hline Quality of analgesia & & Group-B $(\mathbf{n}=30)$ & $\operatorname{Group}-\mathrm{A}(\mathrm{n}=\mathbf{3 0})$ & p Value \\
\hline Onset of analgesia in min $($ Mean \pm SD $)$ & & $8.23 \pm 1.2$ & $4.31 \pm 1.5$ & $<0.05$ \\
\hline \multirow{3}{*}{ Rescue analgesia* } & 0 & 10 & 5 & \multirow{3}{*}{$>0.05$} \\
\hline & 1 & 5 & 2 & \\
\hline & 2 & 12 & 10 & \\
\hline \multirow{4}{*}{ Overall satisfaction regarding analgesia* } & Very Good & 1 & 5 & \multirow[t]{4}{*}{$>0.05$} \\
\hline & Good & 10 & 15 & \\
\hline & Fair & 15 & 9 & \\
\hline & Poor & 4 & 1 & \\
\hline PPI Score $\leq 1[\mathrm{n}(\%)]$ & & $50 \%$ & $78.21 \%$ & $<0.05$ \\
\hline PPI Score $0[\mathrm{n}(\%)]$ & & $3.93 \%$ & $17.5 \%$ & $<0.05$ \\
\hline
\end{tabular}

Table 3: Incidence of side effects Data given as n(\%)

\begin{tabular}{|l|l|l|}
\hline Side effect & $\begin{array}{l}\text { Group-B } \\
(\mathbf{n = 3 0 )}\end{array}$ & $\begin{array}{l}\text { Group-A } \\
(\mathbf{n}=\mathbf{3 0})\end{array}$ \\
\hline Hypotension & $8(22.86)$ & $5(14.29)$ \\
\hline Nausea and vomiting & $5(14.29)$ & $3(8.57)$ \\
\hline Respiratory depression & $3(8.57)$ & $2(5.71)$ \\
\hline Sedation & 0 & $2(5.71)$ \\
\hline Gastrointestinal discomfort & $1(2.86 \%)$ & 0 \\
\hline Total & $22(62.86 \%)$ & $16(45.71)$ \\
\hline
\end{tabular}

Two patients from Group-B and 3 patients from Group-A had transient fall in oxygen saturation that responded to an increase in $\mathrm{FiO}_{2}$. No significant difference was observed between the two groups. Table 4 shows the incidence of side effects in both the groups.

\section{Discussion}

Although different pain mechanism participate in incisional pain, $[3,4]$ acute postoperative pain results in part from sensitization of primary afferent pain receptors at the site of injury, which in turn drives pain and enhanced responsiveness of central neurons [5]. The current results show that postoperative wound local injection of voveron displays a significant morphine sparing effect at 12 and $24 \mathrm{~h}$ after cesarean delivery when compared with the $24 \mathrm{~h}$ after cesarean delivery when compared with the same dose administered intrvenously. After cesarean delivery, systemic administration of voveron (150- to 300-mg daily dose) reduces other analgesic needs by 39-46\% [6-9] using a wound infiltration has allowed a further decrease in morphine use. In the postoperative context, specifically 
in obstetrics, where women want to recover quickly to take care of their baby, an analgesic-sparing effect, which reduces nausea and vomiting as well as sedation, might be beneficial and hasten recovery $[9,10]$. These results contrast with most of those already published on wound infiltration with NSAIDs [11,12]. Although none of these clinical trials involved cesarean delivery or hysterectomy, they all reported the effect from a single dose of NSAID either before or immediately after completion of the surgical procedure. In contrast, our patients benefited from $10 \mathrm{ml}$ postoperative wound local injection.

To date, the modulation of peripheral pain transduction has usually been accomplished by wound infiltration with long-lasting local anesthetics, [13,14] and only a few studies report the use of voveron infiltration. After cesarean delivery $[15,16]$ such local anesthetic infusion provides a mild and short-lasting decrease in pain scores and a significant reduction in postoperative analgesic requirements. Our findings show a shortlasting (12-h) reduction in pain scores but no significant decrease in analgesic needs with intramuscular injection when compared with local saline with voveron local injection. It is possible that the concomitant use of systemic voveron blunted the opioid-sparing effect afforded by the infusion of local anesthetic in our patients.

The current results suggest that local infiltration of voveron allows a better management of postoperative pain than the usual systemic route using intramuscular administration of the drugs. Therefore, these findings questions the relative contribution of central and peripheral mechanisms involved in the postoperative analgesic effect of NSAIDs. In an experimental human model, the central effect accounts for $40 \%$ of the total analgesic effect of systemic voveron [17]. Systemic administration of therapeutic doses of COX inhibitors of associated with a significant reduction in prostaglandin E2 levels both locally at the site of injury and centrally in the cerebrospinal fluid [18,19]. Consequently, the reduction of both local and spinal prostaglandin E2 concentrations is associated with a decrease in postoperative pain [18]. Systemic absorption may have partly accounted for the beneficial effect observed on visceral pain. In a previous clinical trial, [19] small doses of either local or systemic ketorolac, surprisingly, demonstrated delayed but comparable analgesic effect to that of a analgesic of the systemic and the local effect on peripheral prostaglandin E2 levels at the site of injury.[19] These observations suggest not only a central site of action for NSAID analgesia, which is highly sensitive to the effects of NSAIDs and which mediated central hypersensitivity after tissue injury is present, but also that NSAID analgesia might be mediated through local mechanism unrelated to peripheral prostaglandin suppression.

Finally, in addition to the different routes of diclofanec administration, the design of our study, which compared wound infiltration with voveron to systemic administration, did not allow us to exclude an impact of the timing of NSAID administration on the observed analgesic effects. It is possible that circulating sub therapeutic doses of voveron administered at wound reduced postoperative neuronal sensitization more than systemic therapeutic doses.

Beyond the sensitization of damaged tissue, surgical incision also induces central neuronal sensitization and probably the development of residual pain after surgery [20]. Recent studies mention cesarean delivery as a cause of chronic pain [21] representing a significant problem in $6-12 \%$ of patients 10 month after the procedure [22].

Among the established risk factors for development of chronic pain after surgery, the severity of acute postoperative pain is one of the most striking [20,22]. Although this study was not powered to evaluate the incidence and severity of residual pain after cesarean delivery, our results are in agreement with the risk for development of persistent pain after cesarean delivery (an average incidence for the three group of $14 \%$ residual pain at 6 months).

In summary, our results demonstrate that local wound local injection of voveron affords better postoperative pain management after cesarean delivery (greater morphine-sparing effect and decreased early PPI scores) without adverse effects than the same dose administered systemically by intermittent intravenous injections. The current results suggest the presence of peripheral analgesic properties of voveron apart from the systemic effect, mediated either through COX 2 inhibition and decrease of prostaglandin production or through other local mechanisms. In our study, no difference was observed between groups regarding patient satisfaction. All patients had stable vital parameters. The incidence of side effects was remarkably minimal and both groups had comparable in this regard. 


\section{Conclusion}

In conclusion, local local injection is faster acting, more potent and efficient analgesic than intramuscular voveron when used for postoperative pain relief in lower segment cesarean sections.

\section{Funding: Nil,}

Conflict of interest: None.

Permission of IRB: Yes

\section{References}

1. Mankikian B, Cantineau JP, Sartene R, Clergue F, Viars P. Ventilatory pattern and chest wall mechanics during ketamine anesthesia in humans. Anesthesiology. 1986 Nov;65(5):492-9.

2. Brennan TJ. Frontiers in translational research: the etiology of incisional and postoperative pain. Anesthesiology. 2002 Sep;97(3):535-7.

3. Mecklem DW, Humphrey MD, Hicks RW. Efficacy of bupivacaine delivered by wound catheter for postCaesarean section analgesia. Aust $\mathrm{N} \mathrm{Z} \mathrm{J}$ Obstet Gynaecol. 1995 Nov;35(4):416-21.

4. Heyneman CA, Lawless-Liday C, Wall GC. Oral versus topical NSAIDs in rheumatic diseases: a comparison. Drugs. 2000 Sep;60(3):555-74.

5. Olofsson CI, Legeby MH, Nygårds EB, Ostman KM. Diclofenac in the treatment of pain after caesarean delivery. An opioid-saving strategy. Eur J Obstet Gynecol Reprod Biol. 2000 Feb;88(2):143-6.

\section{Siddik SM, Aouad MT, Jalbout MI, Rizk LB, Kamar} GH, Baraka AS. Diclofenac and/or propacetamol for postoperative pain management after cesarean delivery in patientsreceiving patient controlled analgesia morphine. Reg Anesth Pain Med. 2001 JulAug;26(4):310-5.

7. Romsing J, Mysager S, Vilmann P, Sonne J, Larsen NE, Ostergaard D: Postoperative analgesia is not different after local versus systemic administration of meloxicam in patients undergoing inguinal hernia repair. Can J Anaesth 2001; 48:978-84

8. Marret E, Kurdi O, Zufferey P, Bonnet F. Effects of nonsteroidal antiinflammatory drugs on patie nt-controlled analgesia morphine side effects: metaanalysis of randomized controlled trials. Anesthesiology. 2005 Jun;102(6):1249-60.
9.

Kehlet

$\mathrm{H}$.

Postoperative opioid sparing to hasten recovery: what are the issues? Anesthesiology. 2005 Jun;102(6):10835.

10. Rømsing J, Møiniche S, Ostergaard D, Dahl JB. Local infiltration with NSAIDs for postoperative analgesia: evidence for a peripheral analgesic action. Acta Anaesthesiol Scand. 2000 Jul;44(6):672-83.

11. Romsing J, Mysager S, Vilmann P, Sonne J, Larsen NE, Ostergaard D: Postoperative analgesia is not different after local versus systemic administration of meloxicam in patients undergoing inguinal hernia repair. Can J Anaesth 2001; 48:978-84

12. Møiniche S, Mikkelsen S, Wetterslev J, Dahl JB. A qualitative systematic review of incisional local anaesthesia for postoperative pain relief after abdominal operations. Br J Anaesth. 1998 Sep;81(3):377-83.

13. Rawal N. Incisional and intra-articular infusions. Best Pract Res Clin Anaesthesiol. 2002 Jun;16(2):32143.

14. Fredman B, Shapiro A, Zohar E, Feldman E, Shorer S, Rawal N, Jedeikin R: The analgesic efficacy of patient-controlled ropivacaine instillation after cesarean delivery. Anesth Analg 2000; 91:1436-40

15. Mecklem DW, Humphrey MD, Hicks RW. Efficacy of bupivacaine delivered by wound catheter for postCaesarean section analgesia. Aust $\mathrm{N}$ Z J Obstet Gynaecol. 1995 Nov;35(4):416-21.

16. Burian M, Tegeder I, Seegel M, Geisslinger G. Peripheral and central antihyperalgesic effects of diclofenac in a model of human inflammatory pain. Clin Pharmacol Ther. 2003 Aug;74(2):113-20.

17. Buvanendran A, Kroin JS, Berger RA, Hallab NJ, Saha C, Negrescu C, Moric M, Caicedo MS, Tuman KJ. Upregulation of prostaglandin $\mathrm{E} 2$ and interleukins in the central nervous system and peripheral tissue during

and after surgery in humans. Anesthesiology. 2006 Mar;104(3):403-10.

18. Gordon SM, Brahim JS, Rowan J, Kent A, Dionne RA: Peripheral prostanoid levels and nonsteroidal anti- 
inflammatory drug analgesia: Replicate clinical trials in a tissue injury model. Clin Pharmacol Ther 2002; $72: 175-83$

19. Perkins FM, Kehlet H. Chronic pain as an outcome of surgeryA review of predictive factors. The Journal of the American Society of Anesthesiologists. 2000 Oct 1;93(4):1123-33.
20. Almeida EC, Nogueira AA, Candido dos Reis FJ, Rosa e Silva JC. Cesarean section as a cause of chronic pelvic pain. Int J Gynaecol Obstet. 2002 Nov;79(2):101-4.

21. Nikolajsen L, Sorensen HC, Jensen TS, Kehlet H: Chronic pain following caesarean section. Acta Anaesthesiol Scand 2004; 48:111-6

\section{How to cite this article?}

Saraf S, Batra M, Dr Songir S, Dr Thakur KK, Gaikwad M To evaluate and compare analgesic effects of wound infiltration with voveron with intravenous injection in cesarean section. Int J Med Res Rev 2016;4(2):216-221. doi: 10.17511/ijmrr.2016.i02.015. 